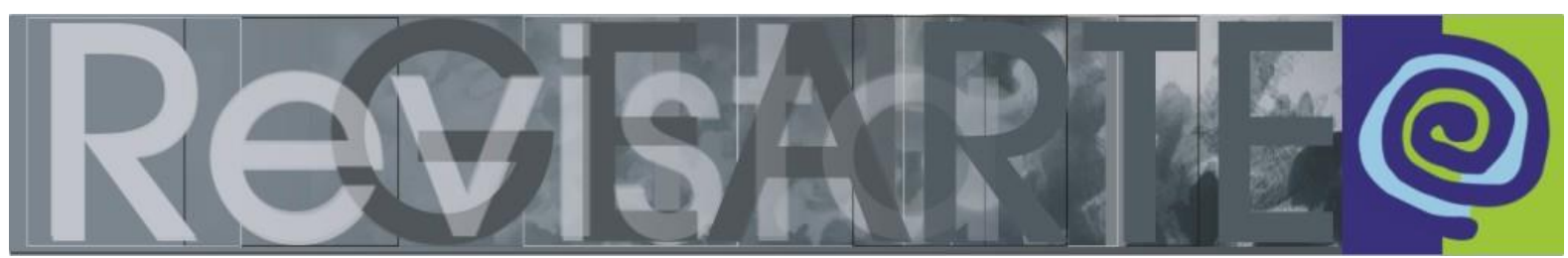

ISSN 2357-9854 | e-ISSN 2596-3198 (online)

\title{
Ensino de Artes Visuais na Infância
}

O debate e a reflexão em torno da relação entre artes visuais e educação das infâncias pode nos conduzir por muitos caminhos, que tanto cruzam distintas concepções de artes e de infâncias quanto são atravessados por dimensões expressivas do viver das crianças em linguagens. As linguagens das artes fazem parte do cotidiano das crianças e dos profissionais que atuam na Educação Infantil e anos iniciais do Ensino Fundamental, envolvendo-os em experiências estésicas e poéticas que transformam e instigam a aproximação lúdica com a coexistência no mundo cultural.

As crianças, como sujeitos de cultura, se produzem - e são produzidas - pelos modos como aprendem a estar no mundo em linguagens. $O$ adulto que as acompanha nesse percurso tão singular quanto plural também é transformado ao exercer o olhar atento e a escuta sensível às situações que envolvem a especificidade das linguagens visuais. Assim, as interfaces entre artes visuais e infâncias apontam para ações em espaços multifacetados e para interações entre crianças e artes, as quais exigem dos adultos ser partícipes de práticas educativas que garantam a oferta de espaços e tempos para que a singularidade das experiências plurais com as linguagens das artes visuais efetivamente ocorra nos projetos pedagógicos da Educação infantil e anos iniciais do Ensino Fundamental.

A proposta de apresentar pesquisas na interface entre artes visuais e educação das infâncias visa destacar a interação das crianças com outras crianças e/ou adultos a partir da produção de sentidos ao que veem e ao que fazem. O debate educacional em torno da produção de sentidos visuais com crianças favorece a reflexão sobre ações pedagógicas que envolvem experiências na linguagem das artes visuais e reflexão sobre a organização de interações que promovem o acesso ao repertório cultural desse campo de conhecimento. Nesse intento, os textos que compõem este número da Revista GEARTE contribuem tanto para a ampliação de estudos e pesquisas quanto para ações cotidianas na perspectiva do Ensino de Artes Visuais ao colocarem os leitores diante das muitas dimensões que as artes podem assumir na educação das crianças. 


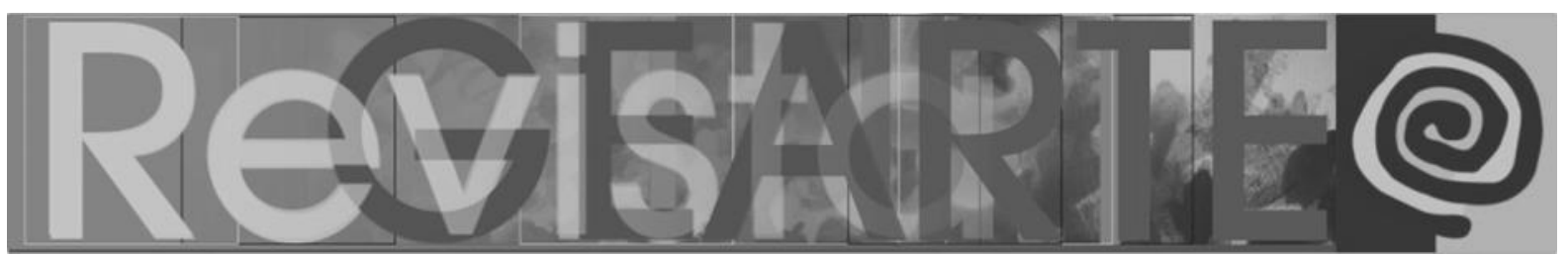

No artigo Na escola, na cidade, no museu: fazer pensar artes visuais na educação Infantil as professoras Dra. Luciana Ostetto, da Universidade Federal Fluminense (Rio de Janeiro, Brasil), e Dra. Maria Isabel Melo, do Agrupamento de Escolas Manuel Ferreira Patrício (Évora, Portugal), defendem uma concepção de arte como processo contínuo e cotidiano de apreender e expressar o mundo, o qual envolve diferentes dimensões do humano e por isso não pode ser reduzida ao produto de um fazer criativo. Se as crianças vivenciam tal processo como produtoras de cultura em interações exploratórias cotidianas, que envolvem linguagens expressivas, seria pertinente a denominação de "ensino da arte" no âmbito da Educação Infantil? Para enfrentar essa discussão e afirmar a relevância da mediação artístico-cultural na primeira etapa da Educação Básica, o texto aproxima as experiências italiana de Reggio Emília e de uma instituição pública de Évora, Portugal.

Em Formação colaborativa: uma possibilidade de habitar o Museu de Arte com a Pequena Infância, a professora Dra. Solange Gabre, da Secretaria Municipal da Educação de Curitiba (Paraná, Brasil), propõe uma discussão sobre a formação continuada do profissional que atua na e com a infância a partir da interlocução com profissionais do Museu Municipal de Arte de Curitiba. O caráter colaborativo da formação, que interliga profissionais da escola e do museu, é apontado como relevante diálogo educacional para favorecer o acesso das crianças pequenas à dimensão artística-cultural promovido por experiências sensíveis promovidas pela arte. $\mathrm{O}$ artigo ressalta a necessidade de fomentar a formação artístico-cultural dos profissionais que atuam como mediadores do acesso das crianças às artes. Para tanto, destaca na formação continuada dos professores a relevância do encontro com a arte e as experiências sensíveis vivenciadas no espaço formativo do museu como abertura para uma cultura colaborativa entre escola e museu de artes.

Já em Quem disse que crianças não sabem fazer curadoria? "Ver diferentes (ver)sões é legal!", a professora Ma. Magali Oliveira Frassão, da InfânciaS Escola de Educação Infantil (Rio Grande do Sul, Brasil), propõe ao leitor vivenciar junto com crianças pequenas a curadoria de uma exposição. A narrativa dos olhares das crianças em relação à escolha do espaço de disposição de objetos e imagens a serem apreciados permite ao adulto leitor ser transportado para a trama das reflexões das crianças sobre o que é 


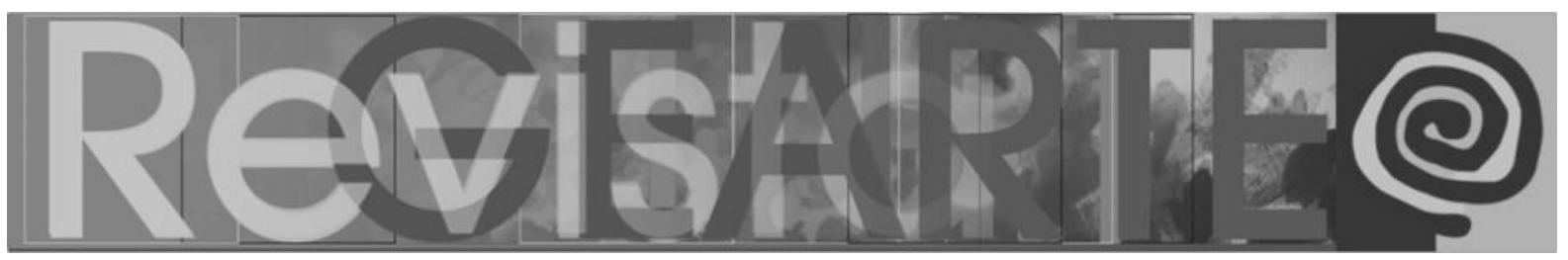

prioritário na organização de uma exposição. Nesse sentido, o texto convida a considerar o que podemos aprender com as crianças sobre organização de espaços no museu.

O artigo Práticas que convidam a olhar e a pensar relações e sentidos construídos pela criança em sua experiência de desenhar na educação infantil, das professoras Dra. Daniele Marques Vieira e Ma. Silvia Pandini, da Universidade Federal do Paraná (Paraná, Brasil), apresenta o desenho como acontecimento na vida da criança que, na ação de desenhar, é movida a interagir com aquilo que a surpreende. A dimensão do inesperado se faz presente no ato de desenhar e a criança, ao ser tomada pelo inusitado, vê e cria novos rumos em seu traçado. As ações das crianças em experiências de imprimir marcas e seu olhar no acontecer do inesperado são enfatizadas pelas autoras como relevante dimensão a ser considerada na organização de situações educativas que postulam as Diretrizes Curriculares Nacionais para a Educação Infantil (DCNEI). Dimensão coerente com os Campos de Experiências por valorizar o gesto do corpo em movimento como possibilidade de constituir versões do mundo pelo pensamento que assume uma forma desenhada.

Amplificando a temática, a professora Dra. Liane Oleques, da Universidade do Estado de Santa Catarina (Santa Catarina, Brasil), no texto Desenho infantil e o Ensino de Artes Visuais: desenhando com crianças com deficiência intelectual), promove o encontro entre o desenvolvimento do desenho na infância e a educação inclusiva. A reflexão em torno de práticas educativas com crianças que apresentam necessidades específicas é tematizada a partir da narrativa do desenvolvimento de experiências com desenho proposta pela educadora para uma criança com deficiência intelectual. A criação e a adequação de propostas de desenvolvimento do desenho são o foco do artigo e podem instigar outros educadores a pensar contextos interativos direcionados à ação de desenhar na especificidade dos sujeitos crianças com necessidades específicas.

Em Diario visual como una simbiosis de expresión artística entre imágenes y texto: material didáctico aplicado al ámbito educativo as professoras Dra. Ana María Marqués Ibáñez, da Universidad de La Laguna (Espanha), Ángela María Bejarano Quintero, da Universidad de La Laguna (Espanha) e Silvia Álvarez Reye, da Universidad de La Laguna (Espanha) apresentam um trabalho com estudantes de graduação na Espanha com a 


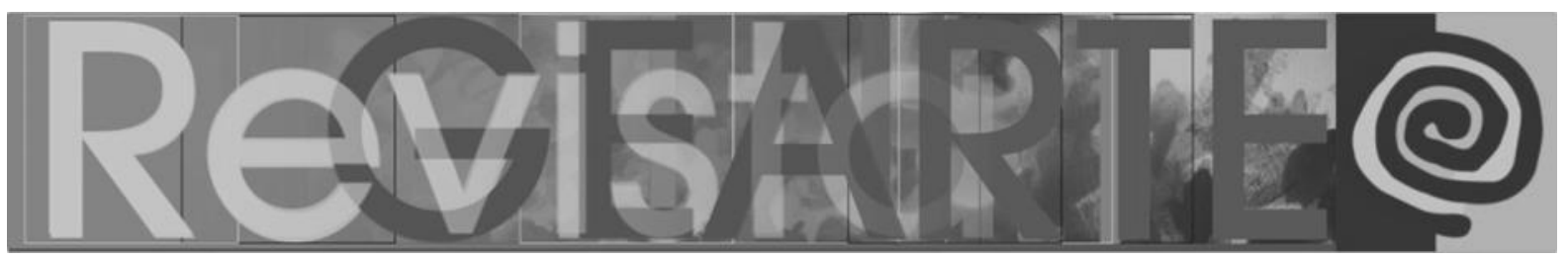

intenção de expor uma possibilidade de marco teórico para o ensino da arte a partir de experiências entre formação docente e expressão das crianças que visam fomentar uma ampla abordagem do uso de imagens na educação das infâncias.

O ensaio visual Projeto Percurso do Artista "até que meus dedos sangrem", da professora Dra. Teresa Poester, da Universidade Federal do Rio Grande do Sul (Rio Grande do Sul, Brasil), traz registros da performance "até que meus dedos sangrem", a qual reuniu 23 artistas convidados por Teresa Poester para a criação de um desenho coletivo, realizado sobre $20 \mathrm{~m}^{2}$ de linóleo branco com 600 canetas Bic vermelhas. A performance foi realizada no dia da Independência do Brasil, com o grupo vestido de preto e usando a cor vermelha como uma forma de causar impacto visual e político.

Queremos agradecer a todos que enviaram seus artigos para compor este número e à artista e professora Dra. Umbelina Barreto pela linda capa. Assim, nesta publicação compartilhamos imagens e ideias, frutos de sonho e paixão humanas, o melhor barro com o qual se pode modelar arte e educação. Boa leitura!

Profa. Dra. Gilvânia Maurício Dias de Pontes ${ }^{1}$ (Universidade Federal do Rio Grande do Norte — UFRN, Natal/RN, Brasil)

Profa. Dra. Sandra Regina Simonis Richter ${ }^{2}$ (Universidade de Santa Cruz do Sul — UNISC, Santa Cruz do Sul/RS, Brasil)

Organizadoras do presente número

1 Professora Titular da Universidade Federal do Rio Grande do Norte, lotada no Núcleo de Educação da Infância, instância do Centro de Educação da UFRN, onde realiza atividades de ensino, pesquisa e extensão. Coordena o Grupo de Pesquisa Arte e Infância (UFRN) e atua em turmas da Educação Infantil e na formação de professores para o trabalho com artes na educação das infâncias. Graduada em Pedagogia pela UFRN; Mestre em Educação pela UFRN; Doutora em Educação pela UFRGS. Fez estágio de pós-doutorado no PPGEdu UFRGS, com estudos sobre mediação em artes visuais na Educação Infantil, sob a supervisão da Profa. Dra. Analice Dutra Pillar. É membro do Grupo de Pesquisa em Educação e Arte (GEARTE). E-mail: gilvaniapontes@hotmail.com

2 Graduada em Educação Artística - Artes Plásticas pela UFRGS, com mestrado e doutorado em Educação pela UFRGS, é professora e pesquisadora do Departamento de Educação da UNISC Universidade de Santa Cruz do Sul e atua na formação de professores para a educação das infâncias. Atualmente é coordenadora adjunta do Programa de Pós-graduação em Educação da UNISC, líder do grupo de pesquisa Estudos Poéticos: Educação e Linguagem e pesquisadora integrante do grupo Peabirú: Educação Ameríndia e interculturalidade. E-mail: srichter@unisc.br 